\title{
Characteristics, management, and outcome of infective endocarditis in the Czech Republic: prospective data from the ESC EORP EURO-ENDO registry
}

\author{
Pazdernik $\mathrm{M}^{1,2}$, Holicka $\mathrm{M}^{3}$, Pelouch $\mathrm{R}^{4}$, Precek $\mathrm{J}^{5}$, Widimsky $\mathrm{J}^{6}$, Pudich $\mathrm{J}^{7}$, Vancata $\mathrm{R}^{8}$, Siranec $\mathrm{M}^{9}$, \\ Bohm $\mathrm{A}^{10}$, Blechova $\mathrm{K}^{11}$, Butta $\mathrm{T}^{12}$, Mikulcova $\mathrm{M}^{13}$, Mikulica $\mathrm{M}^{13}$, Wohlfahrt $\mathrm{P}^{14}$
}

Department of Cardiology, IKEM, Prague, Czech Republic. Michal.Pazdernik@email.cz

\begin{abstract}
INTRODUCTION: Data describing contemporary profile of infective endocarditis (IE) in the Czech Republic are lacking. The aim of this study was to describe the current profile and outcomes of IE patients.

METHODS: Prospectively collected data on consecutive patients admitted for IE diagnosis between April 2016 and March 2018 to 11 main tertiary care cardiac centers in the Czech Republic were used for this analysis.

RESULTS: Among 208 patients, 88 patients (42.3\%) had native valve IE (NVIE), 56 patients (26.9 \%) had prosthetic valve IE (PVIE), and 57 patients $(27.4 \%)$ had intracardiac device-related IE (CDRIE). The mean age was $61.66 \pm 15.54$ years. Staphylococcus aureus was the most common etiological agent of IE (27.4\%), whereas Culture negative IE was present in $26.4 \%$ patients. Surgery was performed during hospitalization in 112 (53.8\%) patients. In-hospital death occurred in $21.2 \%$ patients, while 1-year mortality was $40.3 \%$. In patients, who had an indication for surgery, but the procedure was not performed, mortality was significantly higher $(p=0.002)$.

CONCLUSION: High proportion of culture negative IE and IE related to artificial intra-cardiac materials calls for action. Furthermore, we show that cardiac surgery should be more often contemplated, especially in the presence of risk factors as septic shock and congestive heart failure (Tab. 6, Fig. 1, Ref. 32). Text in PDF www.elis.sk

KEY WORDS: infective endocarditis, mortality, surgery, Czech Republic.
\end{abstract}

\begin{abstract}
${ }^{1}$ Department of Cardiology, IKEM, Prague, Czech Republic, ${ }^{2}$ Department of Cardiology, 2nd Medical School, Charles University, University Hospital Motol, Prague, Czech Republic, ${ }^{3}$ Department of Internal Medicine and Cardiology, University Hospital Brno, Brno, Czech Republic, ${ }^{4} 1$ st Department of Internal Medicine - Cardioangiology, Faculty Hospital in Hradec Kralove, Czech Republic, ${ }^{5}$ Department of Internal Medicine I - Cardiology, University Hospital Olomouc, Czech Republic, ${ }^{6}$ Department of Cardiology, Regional Hospital Liberec, Liberec, Czech Republic, ${ }^{7}$ Department of Cardiovascular Diseases, University Hospital in Ostrava, Czech Republic, ${ }^{8}$ Internal Department II, University Hospital and Faculty of Medicine in Pilsen, Charles University, Pilsen, Czech Republic, ${ }^{9} 2$ nd Department of Internal Cardiovascular Medicine, First Faculty of Medicine, Charles University and General University Hospital in Prague, Czech Republic, ${ }^{10}$ National Institute of Cardiovascular Diseases, Bratislava, Slovakia, ${ }^{11}$ Cardiocenter, Third Faculty of Medicine, Charles University, Prague, Czech Republic, ${ }^{12}$ Department of Cardiology, Second Medical School, Charles University, Motol University Hospital, Prague, Czech Republic, ${ }^{13}$ Cardiovascular Center for Adults, Tomas Bata Regional Hospital, Zlin, Czech Republic, and ${ }^{14}$ Center for Cardiovascular Prevention of the First Faculty of Medicine, Charles University and Thomayer Hospital, Prague, Czech Republic.
\end{abstract}

Adress for correspondence: M. Pazdernik, MD, PhD, FESC, Institute for Clinical and Experimental Medicine (IKEM), CZ-140 21 Prague, Czech Republic.

Phone: +420 602258544

\section{Introduction}

Despite continuous advances in diagnostics and therapeutic management, infective endocarditis (IE) remains a life-threating disease (1). Based on findings from both individual institutional experiences and large, multi-centre studies, a considerable variability in the clinical features of infective endocarditis has been reported (2-6). Only limited data have been published on this topic with the aim to provide a current contemporary profile of the disease in the Czech Republic (6-8). Moreover, well-planned, representative IE epidemiological survey, including main tertiary care hospitals, has never been performed.

Several important factors garnered attention in the recent studies from the region, reporting an increasing incidence of the disease in elderly, change in the predisposing factors, marked shift in aetiology of IE $(3,6,7)$. Nonetheless, these studies suffered from major limitations mainly due to retrospective analysis, small number of recruited patients, and most importantly representing only single or dual centre experience. Dzubova et al attempted to overcome these drawbacks, but including only small regional hospitals in their survey, hence excluding more 
Tab. 1. Patient demographics and characteristics.

\begin{tabular}{|c|c|c|c|c|c|}
\hline & $\begin{array}{c}\text { Total } \\
(n=208)\end{array}$ & $\begin{array}{c}\text { Prosthesis }+ \\
\text { Repair } \\
(n=56)\end{array}$ & $\begin{array}{l}\text { Native } \\
(n=88)\end{array}$ & $\begin{array}{c}\mathrm{PM} / \mathrm{ICD} \\
(\mathrm{n}=57)\end{array}$ & $\mathrm{p}$ \\
\hline Age (years) median & $61.70 \pm 15.44$ & $65.88 \pm 13.24$ & $57.00 \pm 17.34$ & $64.72 \pm 12.72$ & 0.001 \\
\hline Females $(\%)$ & $55(26.4)$ & $14(25.0)$ & $26(29.5)$ & $13(22.8)$ & 0.64 \\
\hline \multicolumn{6}{|l|}{ History of CV disease } \\
\hline Heart failure & $76(36.5)$ & $27(48.2)$ & $16(18.2)$ & $31(54.4)$ & 0.00001 \\
\hline Congenital heart disease & $30(14.4)$ & $4(7.1)$ & $22(25)$ & $2(3.5)$ & 0.0003 \\
\hline Ischemic heart disease & $72(34.6)$ & $26(46.4)$ & $11(12.5)$ & $32(56.1)$ & 0.00001 \\
\hline Atrial fibrillation & $77(37.0)$ & $29(51.8)$ & $18(20.5)$ & $25(43.9)$ & 0.0002 \\
\hline HOCM & $3(1.4)$ & $0(0)$ & $2(2.3)$ & $1(1.8)$ & 0.54 \\
\hline Dilated cardiopathy & $13(6.3)$ & $0(0)$ & $2(2.3)$ & $11(19.3)$ & 0.00002 \\
\hline Known heart murmur & $66(31.7)$ & $29(51.8)$ & $22(25)$ & $13(22.8)$ & 0.001 \\
\hline Previous IE (\%) & $23(11.1)$ & $14(25.0)$ & $6(6.8)$ & $2(3.5)$ & 0.00001 \\
\hline Device therapy & $79(38.0)$ & $12(21.4)$ & $3(3.4)$ & $57(100)$ & 0.00001 \\
\hline \multicolumn{6}{|c|}{ Non-cardiac interventions (last 6 months) } \\
\hline Colonoscopy & $6(2.9)$ & $3(5.4)$ & $3(3.4)$ & $0(0)$ & $0.54)$ \\
\hline Dental procedure & $6(2.9)$ & $1(1.8)$ & $4(4.5)$ & $1(1.8)$ & 0.787 \\
\hline GIT procedure & $8(3.8)$ & $2(3.6)$ & $4(4.5)$ & $1(1.8)$ & 0.884 \\
\hline Urogenital procedure & $7(3.4)$ & $3(5.4)$ & $4(4.5)$ & $0(0)$ & 0.514 \\
\hline \multicolumn{6}{|l|}{ Risk factors } \\
\hline Previous stroke/TIA & $29(13.9)$ & $13(23.2)$ & $6(6.8)$ & $9(15.8)$ & 0.019 \\
\hline Hypertension & $131(63.0)$ & $42(75.0)$ & $46(52.3)$ & $39(68.4)$ & 0.014 \\
\hline COPD/asthma & $33(15.9)$ & $12(21.4)$ & $11(12.5)$ & $9(15.8)$ & 0.361 \\
\hline Chronic renal failure & $47(22.6)$ & $16(28.6)$ & $15(17.0)$ & $15(26.3)$ & 0.212 \\
\hline Haemodialysis & $11(5.3)$ & $1(1.8)$ & $4(4.5)$ & $6(10.5)$ & 0.109 \\
\hline Chronic autoimmune disease & $7(3.4)$ & $2(3.6)$ & $2(2.4)$ & $3(5.3)$ & 0.66 \\
\hline Cancer & $13(6.3)$ & $5(8.9)$ & $4(4.5)$ & $2(3.5)$ & 0.394 \\
\hline Smoking & $60(28.8)$ & $14(25.0)$ & $32(37.6)$ & $12(21.1)$ & 0.073 \\
\hline IVDA & $13(6.3)$ & $4(7.3)$ & $9(10.3)$ & $0(0)$ & 0.047 \\
\hline Alcohol abuse & $17(8.2)$ & $4(7.1)$ & $11(12.9)$ & $2(3.5)$ & 0.130 \\
\hline Immunosuppressive treatment & $6(2.9)$ & $0(0)$ & $4(4.5)$ & $1(1.8)$ & 0.213 \\
\hline Long corticotherapy & $10(4.8)$ & $0(0)$ & $6(6.8)$ & $3(5.3)$ & 0.147 \\
\hline
\end{tabular}

COPD - chronic obstructive pulmonary disease, HOCM - hypertrophic obstructive cardiomyopathy, ICD - implantable cardioverter defibrillator, IE - infective endocarditis, IVDA - intravenous drug abuse, PM - pacemaker, TIA - transient ischemic attack

complicated cases of IE, a non-representative dataset was obtained (7).

Therefore, consecutive cases of IE seen over almost two year period, as part of the ESC EORP Euro-Endo registry (1), enrolled in the majority of main tertiary care referral centres in the Czech Republic were prospectively evaluated in order to provide a current profile of the disease.

\section{Methods}

\section{Study design and data collection}

All data were collected from the prospective multicentre ESCEORP EURO-ENDO registry. The detailed methodology of EURO-ENDO has already been reported (9). All consecutive patients aged $\geq 18$ years with a definite or possible IE were included from April 2016 to March 2018. All participants signed an informed consent. Patients from 11 main tertiary care cardiac centres in the Czech Republic were collected - Prague (Institute for Clinical and Experimental Medicine-IKEM, Faculty Hospital Kralovske Vinohrady, Faculty Hospital Motol, General Faculty Hospital), Faculty Hospital Brno Bohunice, Faculty Hospital Olomouc,
Faculty Hospital Ostrava, Faculty Hospital Plzeň, Faculty Hospital Hradec Králové, Regional Hospital Liberec and Regional Hospital Zlín.

\section{Baseline and follow-up data}

Baseline data included clinical characteristics, biological and microbiological data, imaging data, treatment before admission and during hospitalization, complications under therapy, theoretical indication for surgery (as reported by responsible practitioners), in-hospital surgery/procedures performed (including valvular surgery and both percutaneous and surgical procedures to remove infected intracardiac material), in-hospital mortality. 1-year follow-up data were obtained based on either a telephone call or a clinical examination.

\section{Statistical analysis}

Continuous data with a normal distribution are presented as the mean $\pm \mathrm{SD}$, non-normally distributed variables as median (interquartile range - IQR). Categorical data are shown as frequencies and percentages. Between-group differences were tested using the analysis of variance (ANOVA), Kruskal-Wallis, chi-square tests or Fisher exact test, as appropriate. KaplanMeier curves for time to all cause in hospital death were performed, with log rank test used to compare differences between groups. Univariate Cox regression for in hospital death was used to identify the variables associated with mortality. Variables with a $p<0.1$ in the univariate analysis were used as inputs for multivariate forward Cox regression. Multivariate logistic regression was used to identify clinical variables associated with 1-year mortality. Calculations were done using SPSS version 21 (IBM SPSS Statistics, IBM Corporation, Armonk, New York). All statistical tests were 2-sided with a significance level of 0.05 .

\section{Results}

\section{Patient demographics and characteristics}

A total of 208 patients from 11 main tertiary care cardiac centres in the Czech Republic, admitted to the hospital between April 2016 and March 2018, were enrolled.

The main features of the cohort are illustrated in Table 1. Among 208 patients, 88 patients (42.3\%) had native valve IE (NVIE), 56 patients $(26.9 \%)$ had prosthetic valve IE (PVIE), and 57 patients $(27.4 \%)$ had intracardiac device-related IE (CDRIE). The 7 remaining patients not categorized as PVIE, NVE, or CDRIE corresponded to the combined location of infection 
Tab. 2. Clinical presentation.

\begin{tabular}{|c|c|c|c|c|c|}
\hline & $\begin{array}{c}\text { Total } \\
(n=208)\end{array}$ & $\begin{array}{l}\text { Prosthesis }+ \\
\text { repair } \\
(n=56)\end{array}$ & $\begin{array}{l}\text { Native } \\
(\mathrm{n}=88)\end{array}$ & $\begin{array}{l}\mathrm{PM} / \mathrm{ICD} \\
(\mathrm{n}=57)\end{array}$ & $\mathrm{p}$ \\
\hline \multicolumn{6}{|l|}{ Signs and symptoms } \\
\hline Fever & $149(71.6)$ & $39(69.6)$ & $64(72.7)$ & $43(75.4)$ & 0.787 \\
\hline Cough & $52(25.0)$ & $11(19.6)$ & $23(26.1)$ & $17(29.8)$ & 0.451 \\
\hline Dizziness & $48(23.1)$ & $13(23.2)$ & $22(25)$ & $13(22.8)$ & 0.946 \\
\hline Cerebrovascular event & $13(6.3)$ & $7(12.5)$ & $5(5.7)$ & $1(1.8)$ & 0.062 \\
\hline Syncope & $9(4.3)$ & $3(5.4)$ & $5(5.7)$ & $1(1.8)$ & 0.50 \\
\hline Cardiac murmur & $126(60.6)$ & $42(75)$ & $64(72.7)$ & $18(31.6)$ & $<0.00001$ \\
\hline Congestive heart failure & $73(35.1)$ & $18(32.1)$ & $31(35.2)$ & $21(36.8)$ & 0.867 \\
\hline Cardiogenic shock & $5(2.4)$ & $0(0)$ & $5(5.7)$ & $0(0)$ & 0.037 \\
\hline Septic shock & $18(8.7)$ & $6(10.7)$ & $9(10.2)$ & $1(1.8)$ & 0.123 \\
\hline Osler nodes & $0(0)$ & $0(0)$ & $0(0)$ & $0(0)$ & 1.0 \\
\hline Janeway lesions & $8(3.8)$ & $3(5.4)$ & $5(5.7)$ & $0(0)$ & 0.191 \\
\hline Roth spots & $0(0)$ & $0(0)$ & $0(0)$ & $0(0)$ & 1.0 \\
\hline $\begin{array}{l}\text { Days from onset of symptom } \\
\text { to diagnosis }\end{array}$ & $18(6-40)$ & $17(6-33)$ & $18(5-40)$ & $21(6-42)$ & 0.790 \\
\hline \multicolumn{6}{|l|}{ Complications on admission } \\
\hline Abscess & $37(17.8)$ & $16(28.6)$ & $15(17.0)$ & $4(7.0)$ & 0.01 \\
\hline Pseudo-aneurysm & $3(1.4)$ & $1(1.8)$ & $2(2.3)$ & $0(0)$ & 0.532 \\
\hline Fistula & $5(2.4)$ & $2(3.6)$ & $3(3.4)$ & $0(0)$ & 0.362 \\
\hline New prosthetic dehiscence & $3(1.5)$ & $3(5.4)$ & $0(0)$ & $0(0)$ & 0.093 \\
\hline Perforation & $10(4.8)$ & $0(0)$ & $10(11.4)$ & $0(0)$ & 0.001 \\
\hline Spondylitis & $12(5.8)$ & $6(10.7)$ & $5(5.7)$ & $1(1.8)$ & 0.131 \\
\hline Conduction abnormality & $36(17.3)$ & $12(21.4)$ & $15(17.0)$ & $6(10.5)$ & 0.288 \\
\hline Embolic events & $46(22.1)$ & $17(30.4)$ & $19(21.6)$ & $8(14)$ & 0.11 \\
\hline Pulmonary & $18(8.7)$ & $1(1.8)$ & $10(11.4)$ & $5(8.8)$ & 0.11 \\
\hline Cerebral & $12(5.8)$ & $7(12.5)$ & $4(4.5)$ & $1(1.8)$ & 0.04 \\
\hline Splenic & $12(5.8)$ & $8(14.3)$ & $3(3.4)$ & $1(1.8)$ & 0.008 \\
\hline Coronary & $1(0.5)$ & $0(0)$ & $1(1.1)$ & $0(0)$ & 0.525 \\
\hline Renal & $4(1.9)$ & $3(5.4)$ & $1(1.1)$ & $0(0)$ & 0.093 \\
\hline Hepatic & $1(0.5)$ & $1(1.8)$ & $0(0)$ & $0(0)$ & 0.272 \\
\hline Peripheral & $5(2.4)$ & $2(3.6)$ & $2(2.3)$ & $1(1.8)$ & 0.813 \\
\hline Haemorrhagic stroke & $2(1.0)$ & $2(3.6)$ & $0(0)$ & $0(0)$ & 0.073 \\
\hline \multicolumn{6}{|l|}{ Suspected source of Infection } \\
\hline Health care associated IE & $29(13.9)$ & $10(17.9)$ & $8(9.1)$ & $10(17.5)$ & 0.217 \\
\hline Nosocomial & $13(6.3)$ & $4(7.1)$ & $4(4.5)$ & $5(8.8)$ & 0.583 \\
\hline Non-nosocomial & $45(21.6)$ & $9(16.1)$ & $20(22.7)$ & $12(21.1)$ & 0.620 \\
\hline Community acquired & $94(45.2)$ & $19(33.9)$ & $41(46.6)$ & $29(50.9)$ & 0.163 \\
\hline Intravenous drug abuse associated & $13(6.3)$ & $5(8.9)$ & $8(9.1)$ & $0(0)$ & 0.064 \\
\hline
\end{tabular}

Tab. 3. Microbiology.

\begin{tabular}{lccccc}
\hline & $\begin{array}{c}\text { Total } \\
(\mathrm{n}=208)\end{array}$ & $\begin{array}{c}\text { Prosthesis }+ \\
\text { repair } \\
(\mathrm{n}=56)\end{array}$ & $\begin{array}{c}\text { Native } \\
(\mathrm{n}=88)\end{array}$ & $\begin{array}{c}\text { PM/ICD } \\
(\mathrm{n}=57)\end{array}$ & $\mathrm{p}$ \\
\hline Staphylococcus aureus (MSSA) & $51(24.5)$ & $15(26.8)$ & $19(21.6)$ & $14(24.6)$ & 0.768 \\
Staphylococcus aureus (MRSA) & $8(3.8)$ & $2(3.6)$ & $3(3.4)$ & $2(3.5)$ & 0.999 \\
Staph. Coagulase negative & $32(15.4)$ & $8(14.3)$ & $10(11.4)$ & $12(21.1)$ & 0.275 \\
Streptococcus viridans & $15(7.5)$ & $2(3.6)$ & $12(13.6)$ & $1(1.8)$ & 0.012 \\
Enterococcus & $18(8.7)$ & $7(12.5)$ & $6(6.8)$ & $4(7.0)$ & 0.44 \\
Streptococcus gallolyticus (bovis) & $5(2.4)$ & $2(3.6)$ & $1(1.1)$ & $2(3.5)$ & 0.555 \\
G-bacillus & $9(4.3)$ & $2(3.6)$ & $3(3.4)$ & $4(7.0)$ & 0.548 \\
Culture negative & $53(25.5)$ & $11(19.6)$ & $27(30.7)$ & $15(26.3)$ & 0.342 \\
Coxiella burnetti & $0(0)$ & $0(0)$ & $0(0)$ & $0(0)$ & 1.0 \\
\hline
\end{tabular}

ICD - implantable cardioverter defibrillator, PM - pacemaker

(PVIE+CDRIE/NVIE+CDRIE). These patients were included to total analysis, but not to the groups comparisons analysis.

The mean age was $61.66 \pm 15.54$ years, with NVE associated with younger age $(p=0.001)$. Females represented $26.4 \%$ of the cohort. IE considerably affected population with a previous heart disease $-36.8 \%$ had a history of heart failure, $34.6 \%$ had ischemic heart disease, and $13.9 \%$ had a congenital heart disease. Previous IE was documented in $10.9 \%$ of all the patients and was highly related to PVIE $(p=0.00001)$. There was a history of intravenous drug abuse (IVDA) in $6.5 \%$ patients, none of them was documented in CDRIE.

\section{Clinical presentation}

The location of IE was aortic in 107 $(51.4 \%)$ patients, mitral in $49(23.6 \%)$, tricuspid in $23(11.1 \%)$, and pulmonary in $2(1.0 \%)$. Infective endocarditis affected two or more valves in $7(3.4 \%)$ patients. The median time since the onset of symptoms and IE diagnosis was 18 (6-40) days.

The main characteristics of clinical presentation are displayed in Table 2. Fever occurred in $72.6 \%$ of patients, cardiac murmur was audible in $61.7 \%$ of patients. Congestive heart failure on admission was seen in $34.8 \%$ of patients, equally distributed in all three main groups of the patients. Septic shock developed in $8 \%$ of patients and was mainly related to NVIE and PVIE. Cardiac abscess was observed in $17.4 \%$ of patients, significantly more likely seen in PVIE $(p=0.01)$. New conduction block occurred in $16.4 \%$ of the patients. Embolic events were documented in $21.9 \%$ of all cases, moreover, cerebral, and splenic embolisations were significantly associated with PVIE. Haemorrhagic strokes were seen solely in PVIE patients.

\section{Microbiology}

IE causative agents are displayed in Table 3. Staphylococcus aureus (Staph. aureus) was the most commonly seen etiological agent of IE (27.4\%), followed by Staph. Coagulase negative (14.9\%). Streptococci occurred in $10 \%$, mainly causing NVIE, whereas Enterococci were reported in $8.5 \%$. Culture negative IE cases were reported as high as in $26.4 \%$ of all IE cases.

\section{Complications under therapy}

Main events that occurred during hospitalization are illustrated in the Table 4 . The most frequent complication during hospitalization in our cohort was an acute renal failure $(18.9 \%)$. Embolic events accompanied IE cases in $14.9 \%$ and were less likely documented in CDRIE $(p=0.05)$. Septic 
Tab. 4. Complications under therapy.

\begin{tabular}{|c|c|c|c|c|c|}
\hline & $\begin{array}{c}\text { Total } \\
(n=208)\end{array}$ & $\begin{array}{c}\text { Prosthesis }+ \\
\text { repair } \\
(n=56)\end{array}$ & $\begin{array}{l}\text { Native } \\
(n=88)\end{array}$ & $\begin{array}{c}\text { PM/ICD } \\
(n=57)\end{array}$ & $\mathrm{p}$ \\
\hline Embolic events & $31(14.9)$ & $10(17.9)$ & $17(19.3)$ & $3(5.3)$ & 0.052 \\
\hline Pulmonary & $15(7.2)$ & $4(7.1)$ & $8(9.1)$ & $2(3.5)$ & 0.434 \\
\hline Cerebral & $9(4.3)$ & $3(5.4)$ & $6(6.8)$ & $0(0)$ & 0.142 \\
\hline TIA & $0(0)$ & $0(0)$ & $0(0)$ & $0(0)$ & 1 \\
\hline Stroke & $6(2.9)$ & $2(3.6)$ & $4(4.5)$ & $0(0)$ & 0.278 \\
\hline Spleen & $8(3.8)$ & $5(8.9)$ & $2(2.3)$ & $1(1.8)$ & 0.082 \\
\hline Coronary & $1(0.5)$ & $0(0)$ & $1(1.1)$ & $0(0)$ & 0.525 \\
\hline Renal & $3(1.4)$ & $2(3.6)$ & $1(1.1)$ & $0(0)$ & 0.274 \\
\hline Hepatic & $1(0.5)$ & $1(1.8)$ & $0(0)$ & $0(0)$ & 0.272 \\
\hline Peripheral & $2(1.0)$ & $1(1.8)$ & $1(1.1)$ & $0(0)$ & 0.623 \\
\hline Hemorrhagic stroke & $2(1.0)$ & $1(1.8)$ & $1(1.1)$ & $0(0)$ & 0.623 \\
\hline Spondylitis & $12(5.8)$ & $6(10.7)$ & $5(5.7)$ & $1(1.8)$ & 0.131 \\
\hline $\mathrm{CHF}$ & $24(11.5)$ & $4(7.1)$ & $13(14.8)$ & $6(10.5)$ & 0.36 \\
\hline Cardiogenic shock & $21(10.1)$ & $6(10.7)$ & $11(12.5)$ & $4(7.0)$ & 0.572 \\
\hline Septic shock & 33 (15.9) & $10(17.9)$ & $15(17.0)$ & $6(10.5)$ & 0.477 \\
\hline Mycotic aneurysm & $0(0)$ & $0(0)$ & $0(0)$ & $0(0)$ & 1.0 \\
\hline Acute renal failure & $38(18.3)$ & $8(14.3)$ & $20(22.7)$ & $10(17.5)$ & 0.430 \\
\hline Persistent fever & $14(6.7)$ & $7(12.5)$ & $4(4.5)$ & $3(5.3)$ & 0.157 \\
\hline Positive blood cultures after 48 hours & $17(8.2)$ & $3(5.4)$ & $8(9.1)$ & $4(7.0)$ & 0.700 \\
\hline Increasing vegetation size & $16(7.7)$ & $7(12.5)$ & $2(2.3)$ & $4(7.0)$ & 0.051 \\
\hline New abscess & $18(8.7)$ & $13(23.2)$ & $5(5.7)$ & $0(0)$ & 0.00003 \\
\hline AV block & $9(4.3)$ & $3(5.4)$ & $5(5.7)$ & $0(0)$ & 0.191 \\
\hline Thrombopenia $(<10000)$ & $15(7.2)$ & $6(10.7)$ & $6(6.8)$ & $1(1.8)$ & 0.151 \\
\hline
\end{tabular}

$\mathrm{AV}$ - atrioventricular block, CHF - congestive heart failure, ICD - implantable cardioverter defibrillator, $\mathrm{PM}-$ pacemaker, ICD-TIA - transient ischemic attack

shock developed in $15.4 \%$, whereas a shock of cardiogenic origin appeared in $10.4 \%$. New cardiac abscess was documented in $9 \%$, predominantly affecting PVIE $(\mathrm{p}=0.00003)$. Prosthetic valves were also prone for an increasing size of vegetation $(\mathrm{p}=0.05)$.

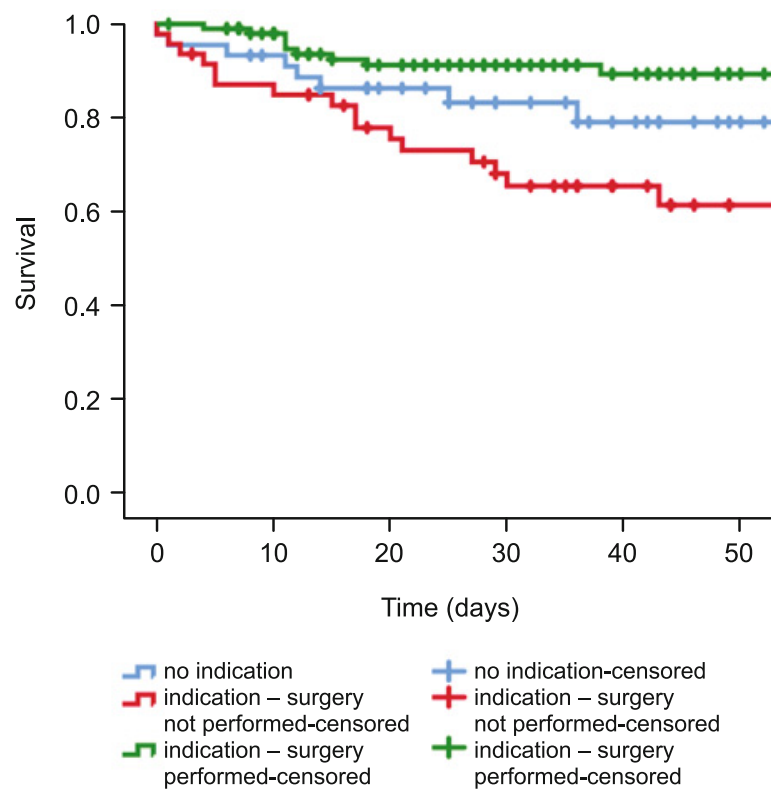

Fig. 1. The Kaplan-Meier curves showing the effect of cardiac surgery on in-hospital mortality.
Cardiac surgery and mortality

Surgery was performed during hospitalization in $112(53.8 \%)$ patients. Following ESC guidelines, theoretical indication for cardiac surgery was reported in 162 $(77.9 \%)$ patients. Among them, surgery was finally performed in $26.8 \%$ of PVIE, $54.5 \%$ of NVE, and surgical or percutaneous extraction in $78.9 \%$ of CDRIE.

In-hospital death occurred in 44 $(21.2 \%)$ patients. The risk of in-hospital mortality was lower (Bonferroni adjusted $\mathrm{p}<0.05)$ in patients with CDRIE $(7.1 \%)$, as compared to both PVIE (30.9 \%) and NVE (23.5\%), respectively. While taking into consideration the patients, who had an indication for surgery, but the procedure was not performed, mortality was significantly higher $(p=0.002)$ (Fig. 1). Predictors of inhospital mortality by multivariable analysis were COPD/asthma, acute renal failure, septic shock, congestive heart failure and conservative treatment of IE episode (Tab. 5).

Overall, 159 patients had a complete 1-year follow up data. Of these, 64 (40.3\%) patients died.

Cardiogenic shock, septic shock, and history of haemodialysis were the independent predictors of increased 1-year mortality. In contrast, performed surgery during IE episode was the only protective factor of an increased 1-year mortality (Tab. 6).

\section{Discussion}

The results of this EURO-ENDO registry provided a unique opportunity to characterize clinical presentation, therapeutic management and outcome of patients with IE in the Czech Republic. No similar extensive and complex descriptive study of this disease has ever been performed in this region.

The principal findings from this IE national registry can be summarized as follows: 1) IE affects predominantly men around 60 years of age, 2) Marked increase in PVIE and CDRIE was observed, representing more than half of IE cases, 3) Staph. aureus continues to be the main causative agent of IE, whereas a high incidence of Culture negative episodes needs further evaluation, 4) an individual thorough assessment towards a surgical treatment is crucial to affect the still high mortality of this disease.

Steadily increasing incidence of IE in older patients reflects progressively aging population in developed countries (10). Elderly people more often have previous cardiac and non-cardiac procedures, which predispose them for infections. The mean age of 61.7 years in our population represent a slightly higher age compared to data obtained from the recent EURO-ENDO registry (59.3 years) (1).

With regards to IE, an increasing trend over time differential with respect to sex has been reported in literature (11). Females represented $26.4 \%$ of the cohort, which is consistent with figures de- 
Tab. 5. Multivariate Cox regression for all-cause in hospital mortality.

\begin{tabular}{lcccc}
\hline & \multirow{2}{*}{ HR } & \multicolumn{2}{c}{$95.0 \% \mathrm{CI}$} & \multirow{2}{*}{$\mathrm{p}$} \\
\cline { 3 - 4 } & & Lower & Upper & \\
\hline COPD/asthma & 3.676 & 1.622 & 8.332 & 0.002 \\
Acute renal failure & 2.789 & 1.323 & 5.877 & 0.007 \\
Septic shock & 6.070 & 2.928 & 12.585 & 0.0001 \\
Congestive heart failure & 2.260 & 0.984 & 5.191 & 0.055 \\
Surgery performed & 0.401 & 0.190 & 0.848 & 0.017 \\
\hline
\end{tabular}

$\mathrm{CI}$ - confidence interval, COPD - chronic obstructive pulmonary disease, HR hazard ratio

Tab. 6. Multivariate logistic regression for all-cause one-year mortality.

\begin{tabular}{lcccc}
\hline & \multirow{2}{*}{ OR } & \multicolumn{2}{c}{$95.0 \% \mathrm{CI}$} & \multirow{2}{*}{$\mathrm{p}$} \\
\cline { 3 - 4 } & & Lower & Upper & \\
\hline Cardiogenic shock & 14.703 & 2.842 & 76.061 & 0.001 \\
Septic shock & 4.105 & 1.274 & 13.229 & 0.018 \\
History of haemodialysis & 14.170 & 1.927 & 153.018 & 0.011 \\
Surgery performed & 0.336 & 0.141 & 0.798 & 0.013 \\
\hline CI - confidence interval, OR - odds ratio & & &
\end{tabular}

rived from dual-centre experience from Czech Republic spanning from 1998-2016, where the $25 \%$ female incidence was reported (7).

The prevalence of Staph. aureus has been steadily increasing over recent years $(12,13)$. Institutional experience from Czech Republic demonstrated noteworthy finding that Staph. aureus accounted for almost one-third of the reported IE episodes in years 1998 2006, and 2009-2016, respectively (14). Similarly, the results of our study, identifying Staph. aureus as a causative agent of IE in $27.4 \%$ episodes, confirmed the previously reported heralded microbiological shift from Viridans group streptococci to Staph. aureus (6).

Cultures are negative in IE for three main reasons - previous administration of antibiotic treatment, inadequate microbiological techniques, and presence of infection with a highly fastidious bacteria or non-bacterial pathogens (15). The incidence of culturenegative IE varies by country, with a higher proportion of culturenegative IE in developing countries (up to $56 \%$ ) $(16,17)$. In contrast, studies from Western Europe identified Culture negative episodes of IE in 12-25\% $(18,19) .26 .4 \%$ incidence of Culture negative endocarditis in the current cohort represents a particularly high proportion, twice as much to previously reported data from the region (14), and warrants further investigations.

The incidence of the prosthetic IE has been increasing over recent years, PVIE represented in our series $26.9 \%$, which is comparable to $26 \%$ of cases in the Euro Heart survey (20), and $25 \%$ in the 2008 French registry (21). The use of intracardiac devices has also increased, and the incidence will likely continue to surge due to an aging population. Hence, this implies an increasing number of possible complications, including infections. The recent study in Spain demonstrated an increasing incidence of IE in pacemakers (22). CDRIE represented $27.4 \%$ of all IE cases in our cohort, which is a substantially higher number compared to other reports from the European countries, including the overall results of EURO-ENDO registry $(1,23,24)$. We may speculate, whether such high proportion of patients with CDRIE might have been affected by involvement of only tertiary care centres in our cohort, which $82 \%(9 / 11)$ out of them possess Cardiac surgery department performing the most complicated cases, including lead extractions. Thus, the profile of the cases was most likely affected by referral bias. Patients with CDRIE have an increased short- and long-term morbidity and mortality $(25,26)$. Nevertheless, our results showed a better survival rates of patients with CDRIE compared to native/prosthetic valve IE cases.

Systemic embolism occurs in $22 \%$ to $50 \%$ of IE cases and represents the highest risk of major cardiovascular events, including death $(2,27)$. In our previous dual-centre experience from the Czech Republic, systemic embolism was documented in total of $36 \%$ IE cases (7). In the recently published results from EUROENDO registry, embolism was already present on admission in $25.2 \%$ patients, additionally, new episodes of embolism during hospitalization occurred as high as in $20.5 \%$ (1). We documented a systemic embolism before and after admission in $22.1 \%$, and $14.9 \%$, respectively. Stratification of the embolic risk should be the indispensable corner stone of each patient assessment in the attempt to decrease the mortality of IE (28-28).

An increasing evidence with regards to the favourable impact of cardiac surgery, especially in cases of Staph. aureus, on survival of the patients with IE has been reported $(1,31,32)$. Indication for surgery in our cohort was consistent with the major reports on the topic, as $53.8 \%$ of the enrolled population underwent a surgical procedure. We agree with the results of the main EURO-ENDO registry analysis, which confirmed the essential role of surgery in patients with IE. In the patients, who had an indication for surgery, but the procedure was not performed, mortality was significantly higher (Fig. 1).

The important role of surgery in our cohort was further confirmed in multivariate survival analyses, as the performed surgery was the only protective factor of in-hospital and 1-year mortality (Tabs 5 and 6). COPD/asthma, acute renal failure, septic shock, and a congestive heart failure were the independent predictors of in-hospital mortality. On top of known risk factors of mortality of IE, haemodialyzed patients represented the most fragile cohort associated with an increased 1-year mortality (Tab. 6).

\section{Conclusions}

The results of this ESC EORP EURO-ENDO registry sub-study provided unique detailed data representing the current profile of IE in Central Europe. Reported heralded microbiological shift from viridans group streptococci to Staph. aureus has been confirmed. A marked increase in the incidence of Culture negative IE and IE related to artificial intra-cardiac materials has been observed. A significantly increased mortality of patients with IE in whom cardiac surgery is indicated, but not performed, warrants further focus.

\section{Limitations}

1.We cannot guarantee that all centres really included all their patients consecutively and prospectively, since the study was based on the volunteer participation of each centre

2.As most centres are tertiary referral centres with cardiac surgical programmes, thus the profile of the cases might have been affected by referral bias. 


\section{References}

1. Habib G, Erba PA, Iung B, Donal E, Cosyns B, Laroche C, Popescu BA, Prendergast B, Tornos P, Sadeghpour A, Oliver L, Vaskelyte J-J, Sow R, Axler O, Maggioni AP, Lancellotti P, EURO-ENDO Investigators. Clinical presentation, aetiology and outcome of infective endocarditis. Results of the ESC-EORP EURO-ENDO (European infective endocarditis) registry: a prospective cohort study. Eur Heart J 2019; 40: 3222-3232.

2. Murdoch DR, Corey GR, Hoen B, Miro JM, Fowler VG, Bayer AS, Karchmer AW, Olaison L, Pappas PA, Moreillon P, Chambers ST, Chu VH, Falco V, Holland DJ, Jones P, Klein JL, Raymond NJ, Read KM, Tripodi MF, Utili R, Wang A, Woods CW, Cabell CH. Clinical presentation etiology, and outcome of infective endocarditis in the 21st century: the International Collaboration on Endocarditis-Prospective Cohort Study. Arch Intern Med 2009; 169: 463-473.

3. Hricak V, Liska B, Kovackova J et al. Trends in risk factors and etiology of 606 cases of infective endocarditis over 23 years (1984-2006) in slovakia. J Chemother 2007; 19 (2): 198-202.

4. Joffre J, Dumas G, Aegerter P et al. Epidemiology of infective endocarditis in French intensive care units over the 1997-2014 period-from CUB-Réa Network. Crit Care 2019; 23 (1): 143. Published 2019 Apr 25.

5. Muñoz P, Kestler M, De Alarcon A et al. Current Epidemiology and Outcome of Infective Endocarditis: A Multicenter, Prospective, Cohort Study. Medicine (Baltimore) 2015; 94 (43): e1816.

6. Pazdernik M, Baddour LM, Pelouch R. Infective endocarditis in the Czech Republic: eight years of experience at one of the country's largest medical centers. J Heart Valve Dis 2009; 18 (4): 395-400.

7. Pazdernik M, Wohlfahrt $\mathbf{P}$, Kautzner $\mathbf{J}$ et al. Clinical predictors of complications in patients with left-sided infective endocarditis: A retrospective study of 206 episodes. Bratisl Med J 2019; 120 (7): 510-515.

8. Dzupova O, Machala L, Baloun R, Maly M, Benes J; Czech Infective Endocarditis Working Group. Incidence, predisposing factors, and aetiology of infective endocarditis in the Czech Republic. Scand J Infect Dis 2012; 44 (4): 250-255.

9. Habib G, Lancellotti P, Erba PA et al. The ESC-EORP EURO-ENDO (European Infective Endocarditis) registry. Eur Heart J Qual Care Clin Outcomes 2019; 5 (3): 202-207.

10. Krčméry V, Hricak V, Fischer $\mathbf{V}$ et al. Etiology, Risk Factors and Outcome of 1003 Cases of Infective Endocarditis from a 33-year National Survey in the Slovak Republic: An increasing proportion of elderly patients. Neuro Endocrinol Lett 2019; 39 (8): 544-549.

11. Correa de Sa DD, Tleyjeh IM, Anavekar NS et al. Epidemiological trends of infective endocarditis: a population-based study in Olmsted County, Minnesota [published correction appears in Mayo Clin Proc 2010 Aug; 85 (8): 772]. Mayo Clin Proc 2010; 85 (5): 422-426.

12. Asgeirsson H, Thalme A, Kristjansson $M$ et al. Incidence and outcome of Staphylococcus aureus endocarditis--a 10-year single-centre northern European experience. Clin Microbiol Infect 2015; 21 (8): 772-778.

13. Hoerr V, Franz M, Pletz MW et al. S. aureus endocarditis: Clinical aspects and experimental approaches. Int J Med Microbiol 2018; 308 (6): 640-652.

14. Pazdernik M, Wohlfahrt $P$, Kautzner J et al. Impact of cardiac surgery on short- and long-term mortality among patients with left-sided Staphylococcus aureus infective endocarditis. Interv Akut Kardiol 2019; 18 (4): 193-199.

15. Lamas CC, Fournier PE, Zappa M et al. Diagnosis of blood culturenegative endocarditis and clinical comparison between blood culture-negative and blood culture-positive cases. Infection 2016; 44 (4): 459-466.
16. Benslimani A, Fenollar F, Lepidi H, Raoult D. Bacterial zoonoses and infective endocarditis, Algeria. Emerg Infect Dis 2005; 11 (2): 216-224.

17. Koegelenberg CF, Doubell AF, Orth H, Reuter H. Infective endocarditis in the Western Cape Province of South Africa: a three-year prospective study. QJM 2003; 96 (3): 217-225.

18. Lamas CC, Eykyn SJ. Blood culture negative endocarditis: analysis of 63 cases presenting over 25 years. Heart 2003; 89 (3): 258-262.

19. Cecchi E, Forno D, Imazio $M$ et al. New trends in the epidemiological and clinical features of infective endocarditis: results of a multicenter prospective study. Ital Heart J 2004; 5 (4): 249-256.

20. Tornos P, Iung B, Permanyer-Miralda G et al. Infective endocarditis in Europe: lessons from the Euro heart survey. Heart 2005; 91 (5): 571-575.

21. Hoen B, Alla F, Selton-Suty $\mathbf{C}$ et al. Changing profile of infective endocarditis: results of a 1-year survey in France. JAMA 2002; 288 (1): 75-81.

22. Carrasco F, Anguita M, Ruiz $M$ et al. Clinical features and changes in epidemiology of infective endocarditis on pacemaker devices over a 27 year period (1987-2013). Europace 2016; 18 (6): 836-841.

23. Sunder S, Grammatico-Guillon L, Lemaignen A et al. Incidence, characteristics, and mortality of infective endocarditis in France in 2011. PLoS One 2019; 14 (10): e223857. Published 2019 Oct 25.

24. Cecchi E, Chirillo F, Castiglione A et al. Clinical epidemiology in Italian Registry of Infective Endocarditis (RIEI): Focus on age, intravascular devices and enterococci. Int J Cardiol 2015; 190: 151-156.

25. Habib A, Le KY, Baddour LM et al. Predictors of mortality in patients with cardiovascular implantable electronic device infections. Am J Cardiol 2013; 111 (6): 874-879.

26. Rizwan Sohail M, Henrikson CA, Jo Braid-Forbes M, Forbes KF, Lerner DJ. Increased long-term mortality in patients with cardiovascular implantable electronic device infections. Pacing Clin Electrophysiol 2015; 38 (2): 231-239.

27. Baddour LM, Wilson WR, Bayer AS et al. Infective Endocarditis in Adults: Diagnosis, Antimicrobial Therapy, and Management of Complications: A Scientific Statement for Healthcare Professionals from the American Heart Association [published correction appears in Circulation 2015 Oct 27; 132 (17): e215] [published correction appears in Circulation 2016 Aug 23; 134 (8): e113] [published correction appears in Circulation 2018 Jul 31; 138 (5): e78-e79]. Circulation 2015; 132 (15): 1435-1486. DOI: 10.1161/CIR.0000000000000296

28. Hubert S, Thuny F, Resseguier $\mathbf{N}$ et al. Prediction of symptomatic embolism in infective endocarditis: construction and validation of a risk calculator in a multicenter cohort. J Am Coll Cardiol 2013; 62 (15): 1384-1392.

29. Rizzi M, Ravasio V, Carobbio A et al. Predicting the occurrence of embolic events: an analysis of 1456 episodes of infective endocarditis from the Italian Study on Endocarditis (SEI). BMC Infect Dis 2014; 14: 230.

30. Olmos C, Vilacosta I, Habib G et al. Risk score for cardiac surgery in active left-sided infective endocarditis. Heart 2017; 103 (18): 1435-1442.

31. Kang DH, Lee S, Kim YJ et al. Long-Term Results of Early Surgery versus Conventional Treatment for Infective Endocarditis Trial. Korean Circ J 2016; 46 (6): 846-850

32. Delahaye F. Is early surgery beneficial in infective endocarditis? A systematic review. Arch Cardiovasc Dis 2011; 104: 35-44. 